\title{
The impact of labor conditions on health conditions of diagnostic nurses
}

\author{
Anna Pavlova*, Vladimir Luchkevich, and Irena Mishkich \\ North-Western State Medical University named after I.I. Mechnikov, Piskarevskij prospect, 47, St. \\ Petersburg, 195067, Russia.
}

\begin{abstract}
The article presents the analysis of the influence of specific professional activities of nurses on their health, quality and productivity when conducting diagnostic testing of patients. We studied the activities and structure of time expenditures of nurses when performing the medical diagnostic testing of patients under their specific operating conditions. The incidence and severity of clinical and functional disorders in nurses that result in reduced physical functioning, emotional state and quality of their professional activity, were studied. Using a dedicated questionnaire ("Professional Burnout (MBI)"), the severity and prevalence of the components of the emotional burnout syndrome was studied. Organizational and preventive measures to optimize their working conditions have been proposed. The developed method of integral evaluation of the performance quality and efficiency has been presented, as well we the process approach model of professional activities of nurses engaged in diagnostic testing of patients.
\end{abstract}

\section{Introduction}

Under the modern medical development conditions, the need for specialists performing diagnostics and ensuring the comfort and safety of patients during testing has considerably increased $[1,2,3,4,12,16,19]$. It is necessary to perform optimization and methodical regulation of the types and quantities of multifunctional activities of these professionals [5, $7,11,13,14,15,17,26]$. The scientific studies analyzing the impact of risk factors and proper operating conditions on the health, quality and efficiency of professional activities of nurses are insufficient $[6,8,22]$.

\section{Materials and Methods}

A comprehensive medical, sociological, hygienic, clinical, statistical and organizational research with the dynamic analysis (2010-2017) has been conducted in healthcare institutions. The operating specifics of nurses was studied based on the time observations $(\mathrm{n}=45)$, medical expert assessment $(\mathrm{n}=108)$ and subjective assessment $(\mathrm{n}=293)$ professional activities, health effects and the development of the emotional burnout syndrome. We

\footnotetext{
*Corresponding author: spb-gigea@mail.ru
} 
analyzed the results of medical tests to identify diseases and symptoms in nurses performing diagnostic testing $[9,24]$.

\section{Results and Discussions}

Professional activities of nurses have their specifics, including: skills of operation using the technically sophisticated diagnostic equipment, knowledge of the diagnostic testing methodology and evaluation of the test results. It has been established that in the structure of time spent on priority activities of nurses in the process of diagnostic testing the highest percentage of total productive time $(94.0 \pm 0.5 \% ; 440.4 \pm 9.0 \mathrm{~min}$.) fell at the instrumental testing $(54.3 \pm 10.0 \% ; 253.9 \pm 45.6 \mathrm{~min}$.), preparation of the workplace, diagnostic equipment, performance of preventive measures, regulation of the priority of patients $(12.3 \pm 2.4 \%$; and $57.5 \pm 11.0 \mathrm{~min}$.), and work with documents (19.8 $\pm 8.8 \%$; $93.0 \pm 41.0 \mathrm{~min}$.), etc.

Insufficient number of nurses with low percent of specialists experienced in various kinds of diagnostic tests $(\chi 2=9.5 ; p=0.003)$ was marked among the adverse organizational factors. Insufficient number of nurses (52.4\%) along with the increased need for functional diagnostic tests leads to production overload, reduces the work motivation and quality of work performed. The intensification of work has an impact on the development of the pronounced fatigue in nurses (OR 3.2 (95\% DI: 1.4-7.0); $\mathrm{p}=0.003$ ) with the occurrence of pain in the lumbar spine (OR 2.3 (95\% DI: 1.04-5.2); $\mathrm{p}=0.04$ ) and cervical spine (OR 3.2 (95\% DI: 1.37.6); $\mathrm{p}=0.02)$.

When assessing the severity of the labor process, the types of physical activities of nurses during the instrumental tests (Table 1) were identified. It was found that the use of nonergonomic furniture increases the physical load on nurses resulting in their reduced physical functioning (frequent movements, leaning over, local load involving the hand and finger muscles) $[18,20]$.

Table 1. Indicators of heavy working process of nurses conducting diagnostic testing of patients

\begin{tabular}{|c|c|c|}
\hline $\begin{array}{l}\text { The indicators of the severity of the working } \\
\text { process }\end{array}$ & $\begin{array}{c}\text { Actual value of } \\
\text { the indicator } \\
\mathrm{Me} \\
{\left[\mathrm{Q}_{1} ; \mathrm{Q}_{3}\right]}\end{array}$ & $\begin{array}{l}\text { Class of working } \\
\text { conditions }\end{array}$ \\
\hline $\begin{array}{l}\text { Spatial movements caused by the operating } \\
\text { process }(\mathrm{km})\end{array}$ & $\begin{array}{c}0.54 \\
{[0.50 ; 0.72]}\end{array}$ & 1 \\
\hline Leaning over by more than $30^{\circ}$ (times per shift) & $\begin{array}{c}101.8 \\
{[87.5 ; 121.8]}\end{array}$ & 3.1 \\
\hline $\begin{array}{l}\text { Stereotypical working movements under the local } \\
\text { load involving hand and finger muscles (times } \\
\text { per shift) }\end{array}$ & $\begin{array}{c}324.0 \\
{[300.0 ; 432.0]}\end{array}$ & 1 \\
\hline
\end{tabular}

This determined the need for reorganization and optimization of the nurse workplace ergonomics .

When assessing the health indicators, a high percentage of nurses with chronic diseases $(66.7 \%)$ and disease development risk factors (10.0\%) was identified. According to medical examinations, the most common (per 100 surveyed) were the diseases of the eye and its appendages, cardio-circulatory system, urogenital system and others (Figure 1). 


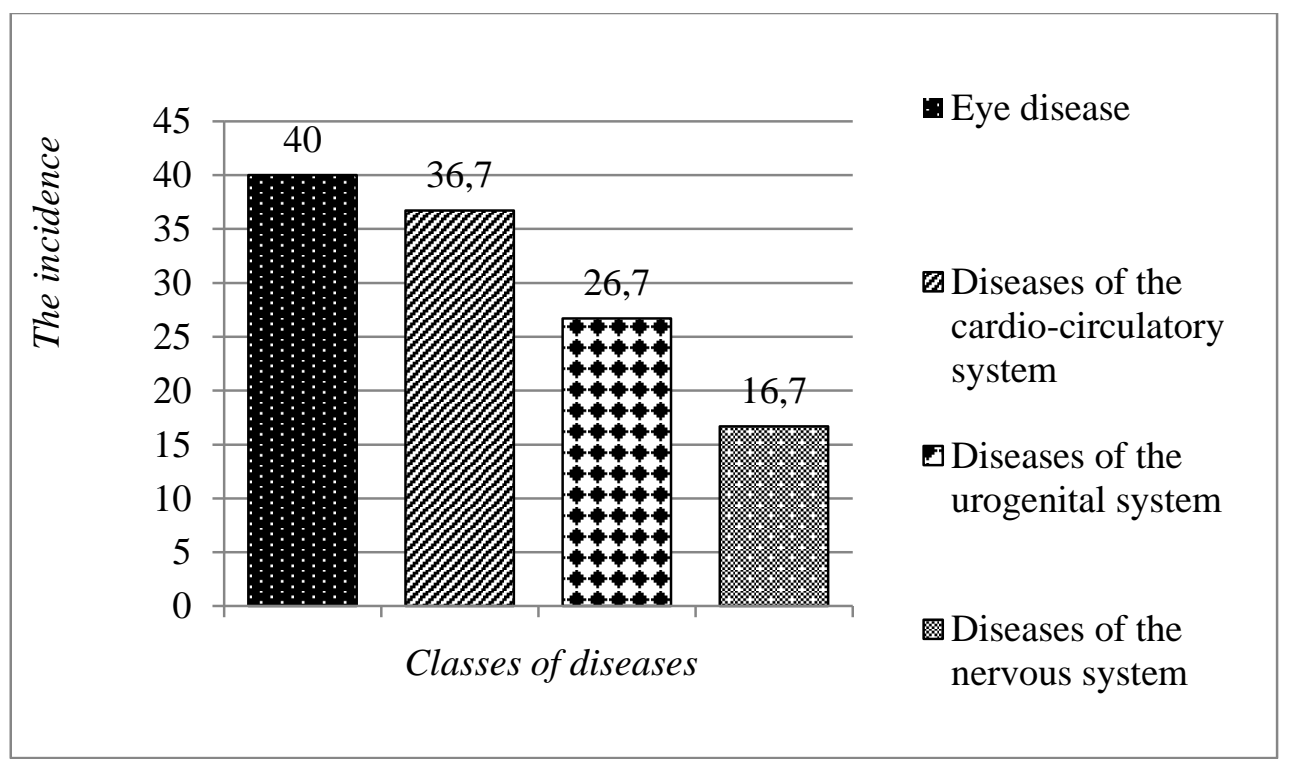

Fig. 1. Health survey of the prevalence of diseases in the nurses (per 100 surveyed)

According to medical and sociological studies, the pronounced signs of changes in mental status (anxiety, restlessness, nervousness, uncertainty) were noted. The assessment of subjective life quality indicators in dynamics for the last five years in nurses revealed the deterioration of general health indicators (17.7 per 100 respondents); appearance of the fatigue (13.9 per 100 respondents); periodic pain manifestations in certain parts of the body (10.5 per 100 respondents) and reduced physical activity (10.6 per 100 respondents). Influence of of the specific professional activity on the psychological state with the increased risk of development of psychological disorders was revealed (OR 3.3 (95\% DI: 1.9-5.5); $\mathrm{p}<0.0001$ ).

The hygienic assessment of working conditions showed that the professional activities of nurses were accompanied by intellectual and emotional loads. To estimate the prevalence and severity of the burnout of nurses we used the questionnaire "Professional Burnout (MBI: Maslach Burnout Inventory)". The development of the burnout components was significantly affected by the presence of emotional overload, frequent stressful situations and poor organization of the operating process due to uneven distribution of the labor load $[9,10,21$, $23,25]$. The adverse production factors, emotional stress, the impact of health indicators on the severity of the burnout components were identified among the nurses, such as high levels of emotional exhaustion (44.3 per 100 surveyed; $p=0.002)$, depersonalization (41.9 per 100 surveyed; $\mathrm{p}=0.02)$ and the low level of reduction of personal achievement (23.9 per 100 surveyed; $\mathrm{p}=0.04$ ).

In the absence of the modern integrated assessment methods of specific activities of nurses in the diagnostic testing of patients, the levels and the algorithm of standard, systematic and organizational management of their working process have been developed. The presented model of the process approach and the algorithm of the organizational activities of nurses in the diagnostic testing stages of patients with assessment of priority activities that affected the quality of diagnostics and optimization of the working conditions, were presented. The criteria for integrated assessment the quality and effectiveness of multi- 
component specific activities (IIQE) of nurses when conducting the diagnostic testing of patients, were developed and substantiated (formula 1).

$$
\mathrm{IIQE}=\mathrm{M}_{\mathrm{lt}}+\mathrm{M}_{\mathrm{lla}}+\mathrm{M}_{\mathrm{qw}}+\mathrm{M}_{\text {mald }}
$$

The proposed method is based on the criterial evaluation (in points) of their work by four modules:

$\mathrm{M}_{\mathrm{lt}}$ - the competence level (basic education, availability of the specialist's certificate, information on qualification, work experience, participation in conferences and public and professional activities);

Mlla - the level of working activity (the volume and types of work performed);

$\mathrm{M}_{\mathrm{qw}}$ - the quality of work performed (the presence of complaints from patients and defects in conducting the diagnostic tests);

$\mathrm{M}_{\text {mald }}$ - medical activity related to the preservation of their own health and labor discipline.

\section{Conclusions}

It has been proven that the production factors had an impact on increased fatigue, expressed in the manifestation of clinical disorders and mental and emotional stress, which contributed to the manifestation of burnout in nurses performing diagnostic testing of patients. The revealed principles allowed justifying the need for the development of the model of medical and organizational interaction and cooperation of nurses and doctors engaged in the provision of patient-oriented, high quality and safe diagnostic aid.

\section{Recommendations}

It is reasonable to use the developed method of integral evaluation of the performance quality and efficiency and the model of the process approach to the organizational and diagnostic activities of nurses, presented in the methodological recommendations in the practical medicine when conducting the diagnostic testing of patients.

\section{References}

1. A.V. Belostotskii, O.V. Gridnev, N.K. Grishina, E.A. Znachkova, Problems of Social Hygiene, Public Health and History of Medicine, 24 (4), 230-5 (2016) doi: 10.1016/0869866X-2016-24-4-230-235

2. F.S Bilalov, G.P Skvirskaya, I.M. Son, Problems of social hygiene, public health and history of medicine, 25(3), 155 - 60 (2017) doi: 10.18821/0869-866X-2017-25-3-155160

3. E.A. Bogush, S.I. Dvoynikov, Problems of Social Hygiene, Public Health and History of Medicine, 27(6), 1080-5 (2019) doi: 10.32687/0869-866X-2019-27-6-1080-1085

4. N.A. Ekimova, L.A. Karaseva, S.I. Dvoynikov, D.G. Tarasov, Clinical and Experimental Surgery Petrovsky journal, 6(4), 82-92 (2018) doi: 10.24411/2308-1198-2018-14012

5. G.V. Fedorova, I.V. Duleva, Problems of Social Hygiene, Public Health and History of Medicine, 26(5), 292-6 (2018) doi: 10.32687/0869-866X-2018-26-5-292-296

6. R.S. Gadzhiev, L.S. Agalarova, Ural Medical Journal, 5(160), 128-133 (2018) doi: 10.25694/URMJ.2018.04.069

7. I.V. Ivanov, Vestnik Roszdravnadzora, 6, 15-23 (2019) doi: 10.35576/2070-7940-20192019-6-15-23 
8. S.V. Merzlyakova, N.V. Kuligina, Russian Journal of Education and Psychology, 9(12), 127-139 (2018) doi: 10.12731/2218-7405-2018-12-127-139

9. A.N. Pavlova, I.A. Mishkich, V.S. Luchkevich, A.N. Chechura, V.V. Zarudnaya, Hygiene and sanitation, 96 (4), 402 - 4 (2017) doi: 10.1882/0016-9900-2017-96-4-402404

10. N.G. Petrova, S.G. Pogosyan, Problems of Social Hygiene, Public Health and History of Medicine, 26(2), 94-7 (2018) doi: 10.1016/0869-866X-2018-26-2-94-97

11. O.I. Sachek, D.A. Tolmachev, Current problems of health care and medical statistics, 2, 213-230 (2019) doi: 10.24411/2312-2935-2019-10037

12. O.V. Sachek, D.A. Tolmachev, Current problems of health care and medical statistics, $\mathbf{1}$, 223-237 (2019) doi: 10.24411/2312-2935-2019-10015

13. D.V. Serov, Eruditio Juvenium, 2, 232-6 (2017) doi: 10.23888/HMJ20172232-236

14. P.P. Shcherbinin, Tambov University Reports Series Natural and Technical Sciences, 21(2), 603-12 (2016) doi: 10.20310/1810-0198-2016-21-2-603-612

15. V.M. Shipova, O.V. Gridnev, S.S. Kutchits, Problems of Social Hygiene, Public Health and History of Medicine, 27(1), 41-4 (2019) doi: 10.32687/0869-866X-2019-27-1-41-44

16. D.A. Tolmachev, Current problems of health care and medical statistics, 2, 295-312 (2019) doi: 10.24411/2312-2935-2019-10044

17. I.V. Uspenskaya, E.V. Manukhina, S.V. Yurina, Eruditio Juvenium, 4, 427-439 (2017) doi: 10.23888/HMJ20174427-439

18. T.Y. AL-Rammah, A.S. Aloufi, S.K. Algaeed, N.S. Alogail, Work, 57(2), 211-219 (2017) doi: 10.3233/WOR-172558

19. Bureau of Labor Statistics: Diagnostic Medical Sonographers and Cardiovascular Technologists and Technicians, Including Vascular Technologists 2016 BLS

URL: https://www.bls.gov/ooh/healthcare/mobile/diagnostic-medical-sonographers.htm

20. K.D. Evans, S.C. Roll, C.D. Hutmire, J.P. Baker, Journal of Diagnostic Medical Sonography, 26(3), 121-129 (2010) doi: 10.1177/8756479310366471

21. V.R. Lorenz, E. Guirardello, Revista Latino-Americana de Enfermagem, 22(6), 926-933 (2014) doi: 10.1590/0104-1169.0011.2497

22. K. Mimura, E. Hosoi, Rinsho Byori The Japanese journal of clinical pathology, 62(5), 478-80 (2014)

23. C.S. Monsalve-Reyes, C.S. Luis-Costas, J.L. Gomez-Urquiza, L. Albendin-Garcia, R. Aguayo, BMC family practice, 19(1) doi: 10.1186/s12875-018-0748-Z

24. S.C. Roll, Evans K.D., C.D. Hutmire, J.P. Baker, Work, 42(3), 355-65 (2012) doi: 10.3233/WOR-2012-1434

25. B. Schooley, N. Hikmet, G. Yorgancioglu, Medicine, 95 (10), 1-6 (2016) doi: 10.1097/MD.0000000000002856

26. Enhancing the role of community health nursing for universal health coverage Geneva World Health Organization 2017 Human Resources for Health Observer Series N 18 Licence: CC BY-NC-SA 3.0 IGO URL: https://www.who.int/hrh/resources/healthobserver18/en/ 